\title{
The paradoxical response to short-acting bronchodilator administration in patients with chronic obstructive pulmonary disease
}

\author{
Hong-Joon Shin ${ }^{1}$, Tae-Ok Kim ${ }^{1}$, Yu-Il Kim ${ }^{1}$, Sang-Hoon Kim², Hyun Kuk Kim ${ }^{3}$, Yong-Hyun Kim ${ }^{4}$, \\ Min Kwang Byun ${ }^{5}$, Ki-Suck Jung ${ }^{6}$, Kwang-Ha Yoo ${ }^{7}$, Jae Seung Lee ${ }^{8}$, Sung-Chul Lim ${ }^{1}$; KOCOSS Cohort \\ Study Group
}

${ }^{1}$ Division of Pulmonary Medicine, Department of Internal Medicine, Chonnam National University Hospital, Kwangju, South Korea; ${ }^{2}$ Department of Internal Medicine, Eulji General Hospital, Eulji University School of Medicine, Seoul, South Korea; ${ }^{3}$ Division of Pulmonary and Critical Care Medicine, Department of Internal Medicine, Inje University Haeundae Paik Hospital, Busan, South Korea; ${ }^{4}$ Division of Allergy and Pulmonology, Department of Internal Medicine, Bucheon St Mary's Hospital, College of Medicine, The Catholic University of Korea, Bucheon, South Korea; ${ }^{5}$ Division of Pulmonology, Department of Internal Medicine, Gangnam Severance Hospital, South Korea; ${ }^{6}$ Division of Pulmonary Medicine, Department of Internal Medicine, Hallym University Sacred Heart Hospital, Hallym University Medical School, Anyang, South Korea; ${ }^{7}$ Division of Pulmonary and Critical Care Medicine, Department of Internal Medicine, Konkuk University Medical Center, Konkuk University School of Medicine, Seoul, South Korea; ${ }^{8}$ Department of Pulmonary and Critical Care Medicine, Asan Medical Center, University of Ulsan College of Medicine, South Korea

Contributions: (I) Conception and design: HJ Shin, SC Lim; (II) Administrative support: HJ Shin, TO Kim, YI Kim, SC Lim; (III) Provision of study materials or patients: SH Kim, HK Kim, YH Kim, MK Byun, KS Jung, KH Yoo, JS Lee; (IV) Collection and assembly of data: SH Kim, HK Kim, YH Kim, MK Byun, KS Jung, KH Yoo, JS Lee; (V) Data analysis and interpretation: HJ Shin, TO Kim, YI Kim, SC Lim; (VI) Manuscript writing: All authors; (VII) Final approval of manuscript: All authors.

Correspondence to: Sung-Chul Lim. Department of Internal Medicine, Chonnam National University Hospital, 671 Jaebongro, Dongku, Gwangju 501-757, Korea. Email: 1scmd@jnu.ac.kr.

Background: There are a few studies about paradoxical bronchodilator response (BDR), which means a decrease in forced expiratory volume in 1 second $\left(\mathrm{FEV}_{1}\right)$ or forced vital capacity (FVC) after short-acting bronchodilator administration in patients with chronic obstructive pulmonary disease (COPD). We evaluated the effect of paradoxical BDR on the clinical outcomes of COPD patients in South Korea.

Methods: We analyzed the KOrea COpd Subgroup Study team (KOCOSS) cohort data in South Korea between January 2012 and December 2017. BDR was defined as at least a 12\% and 200-mL reduction in $\mathrm{FEV}_{1}$ or FVC after bronchodilator administration.

Results: A total of 1,991 patients were included in this study. A paradoxical BDR was noted in 57 (2.9\%) patients and was independently associated with worse dyspnea and poor quality of life. High C-reactive protein (CRP) levels were associated with a paradoxical BDR (OR, 1.05; 95\% CI, 1.01-1.09; P=0.003). However, paradoxical BDR was not associated with severe acute exacerbations. Pre-bronchodilator $\mathrm{FEV}_{1}$ (L) showed a higher area under the curve (AUC) for predicting severe acute exacerbations than the postbronchodilator $\mathrm{FEV}_{1}(\mathrm{~L})$ in the paradoxical BDR group (0.788 vs. 0.752).

Conclusion: A paradoxical reduction of $\mathrm{FEV}_{1}$ or $\mathrm{FVC}$ after bronchodilator administration may be associated with chronic inflammation in the airway and independently associated with worse respiratory symptoms and poor quality of life.

Keywords: Bronchodilator; chronic obstructive pulmonary disease (COPD); C-reactive protein (CRP); exacerbation; paradoxical

Submitted Feb 22, 2020. Accepted for publication Nov 12, 2020.

doi: $10.21037 /$ jtd-20-985

View this article at: http://dx.doi.org/10.21037/jtd-20-985

(c) Journal of Thoracic Disease. All rights reserved. 


\section{Introduction}

Post-bronchodilator spirometry is required for the diagnosis of chronic obstructive pulmonary disease (COPD), but the role of bronchodilator response (BDR) is unclear in COPD (1). Positive bronchodilator reversibility is no longer recommended as a treatment option for COPD, and there is no standard definition yet $(2,3)$. In addition, positive bronchodilator reversibility does not predict the clinical outcomes of long-term use of bronchodilators and inhaled corticosteroid (ICS) (4). However, lung function may be paradoxically reduced after bronchodilator administration. In the previous study, COPD patients with paradoxical reductions in forced expiratory volume in 1 second $\left(\mathrm{FEV}_{1}\right)$ or forced vital capacity (FVC) after bronchodilator spirometry had poor qualities of life and frequent severe exacerbations (5). The incorrect use of inhalers and bronchospasm in response to the ingredients in inhalers have been suggested, but the mechanism of paradoxical BDR is still unclear (6-8). To the best of our knowledge, no study has assessed paradoxical BDR and the clinical outcomes of COPD in an Asian population.

In this study, we aimed to evaluate the effect of paradoxical BDR on the clinical outcomes of COPD patients in the KOrea COpd Subgroup Study team (KOCOSS) cohort (NCT02800499).

\section{Methods}

\section{Study design and patients}

The KOCOSS cohort is an ongoing, longitudinal, prospective, non-interventional, and observational study within the South Korean patients with COPD. We recruited and analyzed cohort data between January 2012 and December 2017. Inclusion criteria were as follows: age $>40$ years; symptoms including cough, sputum, and dyspnea; and post-bronchodilator $\mathrm{FEV}_{1} / \mathrm{FVC}<0.7$. Exclusion criteria were as follows: asthma; inability to complete pulmonary function test; myocardial infarction or cerebrovascular event within the previous 3 months; pregnancy; rheumatoid arthritis; malignancy (metastatic cancer, leukemia, lymphoma); irritable bowel syndrome; and use of systemic steroids over 8 weeks for a reason other than COPD.

The protocol which was conducted according to the principle expressed in the Declaration of Helsinki was approved by the institutional review board (IRB) at each participating center (CNUH-2012-070). All patients provided written informed consent for participation in the study.

The initial evaluation for all patients included pulmonary function tests, 6-minute walk distance (6MWD), COPD Assessment Test (CAT), modified Medical Research Council (mMRC) dyspnea scale, COPD-specific version of St. George's Respiratory Questionnaire (SGRQ-C), exacerbations in the previous 12 months, smoking status, medications, and comorbidities. Acute exacerbation of COPD was defined as the worsening of any respiratory symptom, including increased sputum volume, purulence, or increased dyspnea. Severe exacerbation was defined as the need for hospitalization or visiting the emergency room due to acute exacerbation of COPD.

\section{Pulmonary function, disease severity, and exercise assessments}

Spirometry and 6MWD were performed according to previous studies $(9,10)$. COPD severity was categorized using spirometry alone, in accordance with the 2017 GOLD guidelines. Stage I COPD: $\mathrm{FEV}_{1} \geq 80 \%$ predicted; stage II: $\mathrm{FEV}_{1} \leq 50 \%$ to $80 \%$ predicted; stage III: $\mathrm{FEV}_{1} \leq 30 \%$ to $50 \%$ predicted; and stage IV: $\mathrm{FEV}_{1}<30 \%$ predicted. The paradoxical BDR was defined as $\geq 12 \%$ and $200 \mathrm{~mL}$ reduction in $\mathrm{FEV}_{1}$ or FVC, respectively, or in both, after the administration of a bronchodilator, as described by previous reports and modified from the adapted American Thoracic Society criteria for BDR (11). The reduction in percentage was assessed as follows (5):

$$
\frac{\text { postbronchodilator } F E V_{1}(\mathrm{~L})-\text { postbronchodilator } F E V_{1}(\mathrm{~L})}{\text { postbronchodilator } F E V_{1}(\mathrm{~L})} \times 100
$$

\section{Statistical analyses}

Descriptive statistics were reported as the mean and standard deviation for descriptive variables. For categorical variables, the number of patients per category and frequency of responses were recorded. Continuous variables with different severity classifications were analyzed using a twosample $t$-test and $\chi^{2}$ tests, and Fisher's exact test was used for comparing categorical variables. Bivariate and multivariate linear regression models were used to assess the independent effects of paradoxical BDR status in the cohort in relation to mMRC, CAT, SGRQ-C, and 6MWD, with age, sex, body mass index (BMI), smoking burden, and pre-bronchodilator $\mathrm{FEV}_{1}$ as covariates. To identify the factors predictive of paradoxical BDR, the variables that differed significantly between the paradoxical BDR and no-paradoxical BDR 


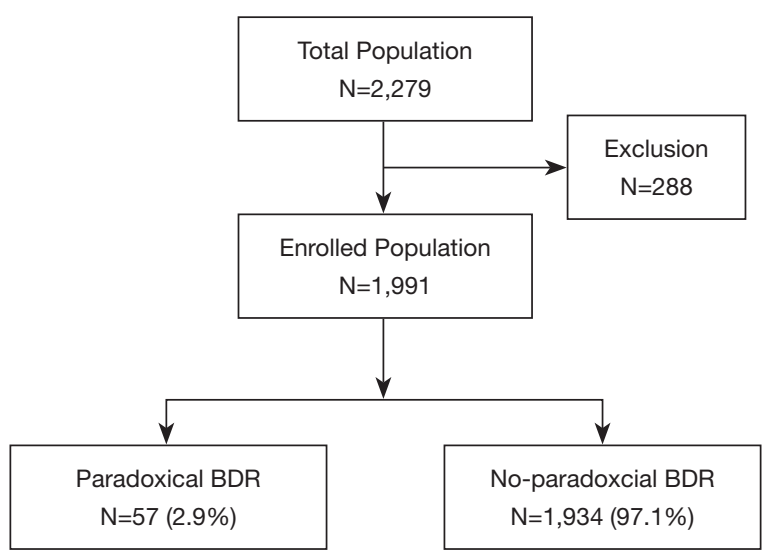

Figure 1 Study flow chart.

groups were included for univariate analysis with logistic regression. Subsequent multivariate logistic regression analysis using the backward method included variables with $\mathrm{P}<0.1$ in the univariate analysis. Pre-bronchodilator and post-bronchodilator $\mathrm{FEV}_{1}(\mathrm{~L})$ were assessed to predict acute severe exacerbations using the receiver operating characteristic curve and area under the curve (AUC) in paradoxical BDR groups. We evaluated the influence of paradoxical BDR on severe acute exacerbations by matching patients according to covariates of age, sex, current smoking status, BMI, pre-bronchodilator $\mathrm{FEV}_{1}$ (\% predicted), CAT, SGRQ-C, comorbid diseases (heart disease, diabetes, hypertension, and previous 1-year acute exacerbation), and previously used inhalers [long-acting muscarinic antagonist (LAMA), long-acting $\beta_{2}$-agonist (LABA), and ICS]. Propensity score matching was performed with 1:3 nearest neighbor matching without replacement. The caliper was 0.05 , and the absolute standardized differences of the mean were within 0.1 for all variables. Statistical analyses were performed using SPSS 23.0. Propensity score matching was performed using IBM SPSS 23.0 and $\mathrm{R}$ version R3.1.0 (R Foundation for Statistical Computing, Vienna, Austria). $\mathrm{P}<0.05$ was considered statistically significant.

\section{Results}

We enrolled 1,991 patients in this study from 2,279 patients recruited during the cohort period (Figure 1). Two hundred and eighty-eight patients were excluded; 82 patients recorded $\mathrm{FEV}_{1} / \mathrm{FVC}$ of $>0.7$ and 206 patients had missing $\mathrm{FEV}_{1}$ or FVC data at the time of enrollment.

We found $57(2.9 \%)$ patients had a paradoxical BDR. Mean age was 68.8 years in the paradoxical BDR and
69.2 years in the no-paradoxical BDR group (Table 1). The male sex was predominant representing $87.7 \%$ of the paradoxical BDR group and $90.8 \%$ of the no-paradoxical BDR group. There were no differences in underlying diseases between groups. Pre-bronchodilator $\mathrm{FEV}_{1}(\mathrm{~L})$ was higher in the paradoxical BDR group than the noparadoxical BDR group. However, post-bronchodilator $\mathrm{FEV}_{1}$ and FVC were significantly higher in the noparadoxical BDR group than the paradoxical BDR group.

A multivariate analysis that adjusted for age, sex, BMI, pack-years of smoking, and pre-bronchodilator $\mathrm{FEV}_{1}$ (L), showed that the paradoxical BDR was independently associated with higher mMRC, CAT, and SGRQ-C scores (Table 2).

To identify the factors predictive of paradoxical BDR, the variables that differed significantly between the two groups in Table 1 were selected; these were $\mathrm{DL}_{\mathrm{CO}}(\%$ predicted), vital capacity, CRP, and pre-bronchodilator $\mathrm{FEV}_{1}(\mathrm{~L}) . \mathrm{DL}_{\mathrm{CO}}$ (\% predicted), vital capacity, CRP, and prebronchodilator $\mathrm{FEV}_{1}(\mathrm{~L})$ were associated with paradoxical $\mathrm{BDR}$ in the univariate logistic regression analysis. However, multivariate logistic regression analysis using the backward method revealed that high CRP [odds ratio (OR), 1.05; 95\% confidence interval (CI), 1.01-1.09; $\mathrm{P}=0.003]$ and $\mathrm{DL}_{\mathrm{CO}}(\%$ predicted) (OR, 0.95; 95\% CI, 0.92-0.98; $\mathrm{P}=0.004)$ were significantly associated with paradoxical BDR as shown in Table 3 (Nagelkerke $R^{2}=0.218$ ).

A paradoxical BDR was not associated with severe acute exacerbation during the 1-year period after logistic regression analysis with adjusting for confounding factors (Table 4). In addition, we used propensity score matching with variables to assess whether a paradoxical BDR was associated with severe acute exacerbation of COPD within 
Table 1 Baseline characteristics of the no-paradoxical and paradoxical BDR groups

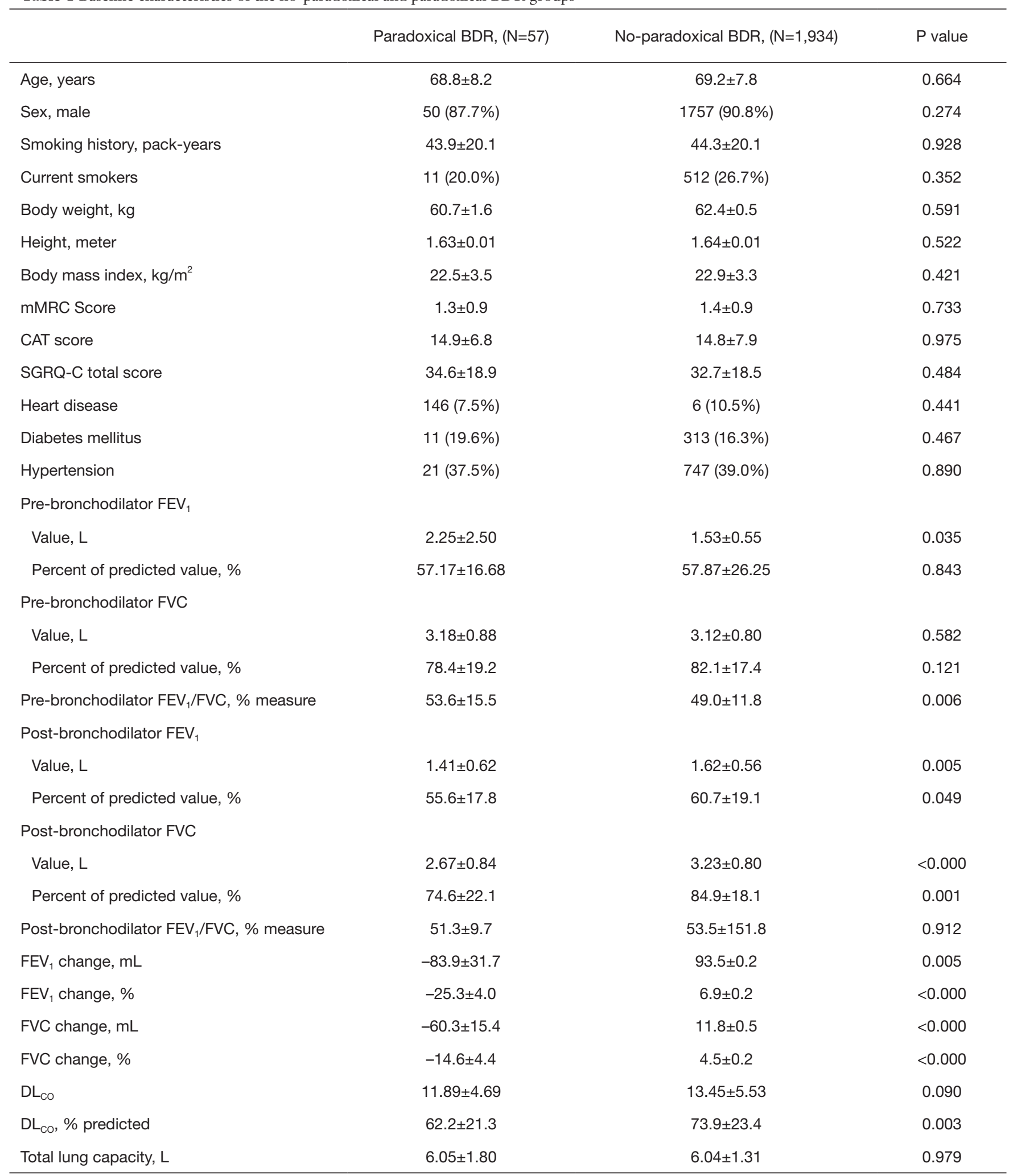

Table 1 (continued) 
Table 1 (continued)

\begin{tabular}{|c|c|c|c|}
\hline & Paradoxical BDR, $(\mathrm{N}=57)$ & No-paradoxical BDR, $(\mathrm{N}=1,934)$ & $P$ value \\
\hline Vital capacity, L & $2.92 \pm 0.77$ & $3.27 \pm 0.79$ & 0.030 \\
\hline Vital capacity, \% predicted & $79.2 \pm 16.7$ & $92.2 \pm 45.6$ & 0.154 \\
\hline Inspiratory capacity, L & $2.22 \pm 1.15$ & $1.84 \pm 0.60$ & 0.135 \\
\hline Functional residual capacity & $84.05 \pm 0.95$ & $4.15 \pm 1.19$ & 0.695 \\
\hline Functional residual capacity, \% predicted & $124.5 \pm 27.2$ & $129.2 \pm 42.6$ & 0.605 \\
\hline Residual volume, L & $2.85 \pm 1.15$ & $2.77 \pm 2.07$ & 0.857 \\
\hline Residual volume, \% predicted & $132.3 \pm 48.0$ & $125.3 \pm 58.3$ & 0.560 \\
\hline I & $5(8.8 \%)$ & $281(14.5 \%)$ & 0.195 \\
\hline II & $30(52.6 \%)$ & $1083(56.0 \%)$ & \\
\hline III & $17(29.8 \%)$ & $491(25.4 \%)$ & \\
\hline IV & $5(8.8 \%)$ & $79(4.1 \%)$ & \\
\hline 6MWD, meter & $383.2 \pm 127.6$ & $377.3 \pm 116.8$ & 0.779 \\
\hline Eosinophil, \% & $3.23 \pm 3.59$ & $3.35 \pm 3.41$ & 0.818 \\
\hline C-reactive protein, $\mathrm{mg} / \mathrm{dL}$ & $11.6 \pm 18.2$ & $2.7 \pm 7.5$ & 0.055 \\
\hline \multicolumn{4}{|l|}{ Acute exacerbation } \\
\hline Inhaled corticosteroid & $20(35.1 \%)$ & $756(39.1 \%)$ & 0.584 \\
\hline
\end{tabular}

Data are presented as number (\%) or mean (SD). BDR, bronchodilator response; mMRC, modified Medical Research Council; CAT, COPD assessment test; SGRQ-C, COPD-specific version of St. George's Respiratory Questionnaire; FEV ${ }_{1}$, forced expiratory volume in 1 second; L, liters; FVC, forced vital capacity; $\mathrm{DL}_{\mathrm{co}}$, diffusing capacity for carbon monoxide; GOLD, global initiative for chronic obstructive lung disease; 6MWD, 6-minute walk distance. Missing values [n]; smoking history [747], current smokers [20], body mass index [6], mMRC score [17], CAT score [77], SGRQ-C total score [46], diabetes mellitus [15], hypertension [19], DLco [393], total lung capacity [690], vital capacity [687], inspiratory capacity [848], functional residual capacity [777], residual volume [682], residual volume/total lung capacity [752], 6MWD [493], eosinophil [394], C-reactive protein [1,074].

1 year. After 1:3 matching analysis, a paradoxical BDR was not associated with severe acute exacerbations of COPD.

The receiver operating characteristic curve predicting severe acute exacerbation during 1 year showed that prebronchodilator $\mathrm{FEV}_{1}(\mathrm{~L})$ had a higher AUC than postbronchodilator $\mathrm{FEV}_{1}(\mathrm{~L})$ in the paradoxical BDR group
(AUC, 0.788; 95\% CI, 0.649-0.927; $\mathrm{P}=0.040$ vs. AUC, 0.752; 95\% CI, 0.567-0.936; $\mathrm{P}=0.094$, respectively).

\section{Discussion}

In this cohort study, we described the characteristics of 
Table 2 Univariate and multivariate analysis of the paradoxical response and respiratory symptoms

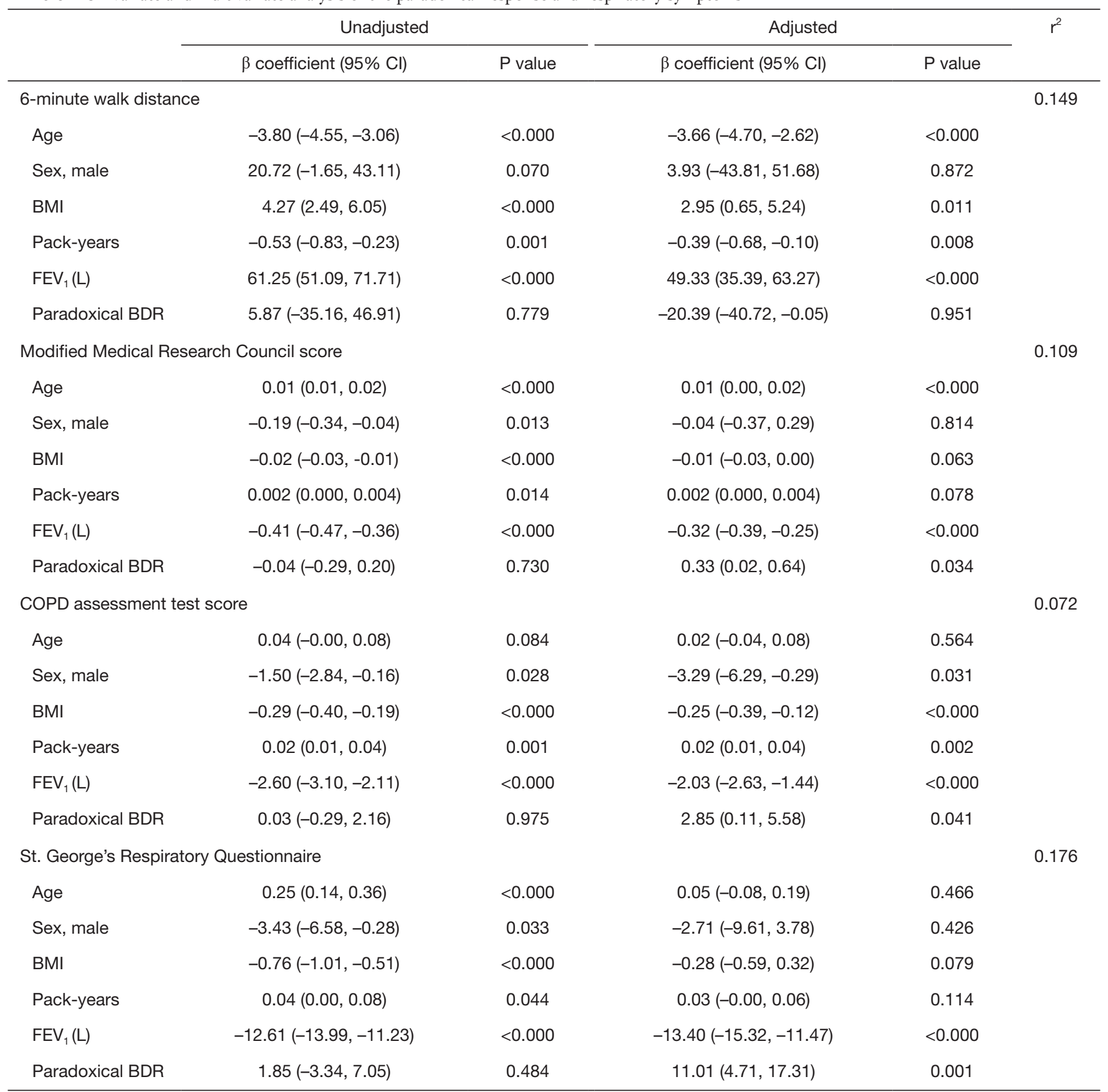

$\mathrm{BMI}$, body mass index; $\mathrm{FEV}_{1}$, forced expiratory volume in 1 second; L, liters; BDR, bronchodilator response; COPD, chronic obstructive pulmonary disease; $\mathrm{Cl}$, confidence interval.

patients with COPD who exhibit a paradoxically reduced $\mathrm{FEV}_{1}$ or FVC after bronchodilator administration. We found that the paradoxical BDR was independently associated with higher mMRC, CAT, and SGRQ-C scores, and an elevated CRP level was associated with paradoxical BDR after bronchodilator administration. Prebronchodilator $\mathrm{FEV}_{1}(\mathrm{~L})$ was more predictive of severe acute exacerbations of COPD than post-bronchodilator $\mathrm{FEV}_{1}(\mathrm{~L})$ in the paradoxical BDR group.

We found that 57 (2.9\%) of 1,991 patients with COPD 
Table 3 Predictive factors for a paradoxical bronchodilator response

\begin{tabular}{|c|c|c|c|}
\hline Variables & Odds ratio & $95 \% \mathrm{Cl}$ & $P$ value \\
\hline $\mathrm{DL}_{\mathrm{co}}(\%$ predicted $)$ & 0.97 & $0.96-0.99$ & 0.003 \\
\hline Vital capacity & 0.56 & $0.33-0.94$ & 0.031 \\
\hline C-reactive protein & 1.04 & $1.02-1.07$ & $<0.000$ \\
\hline Pre-bronchodilator FEV (L) & 3.07 & $2.00-4.72$ & $<0.000$ \\
\hline \multicolumn{4}{|l|}{ Multivariate analysis } \\
\hline C-reactive protein & 1.05 & $1.01-1.09$ & 0.003 \\
\hline $\mathrm{DL}_{\mathrm{co}}(\%$ predicted $)$ & 0.95 & $0.92-0.98$ & 0.004 \\
\hline
\end{tabular}

$\mathrm{DL}_{\mathrm{co}}$, diffusing capacity for carbon monoxide; $\mathrm{FEV}_{1}$, forced expiratory volume in 1 second; $\mathrm{L}$, liters; $\mathrm{Cl}$, confidence interval.

Table 4 Predictive factors for severe 1-year acute exacerbation

\begin{tabular}{|c|c|c|c|}
\hline Variables & Odds ratio & $95 \% \mathrm{Cl}$ & $P$ value \\
\hline Paradoxical BDR ${ }^{\mathrm{a}}$ & 0.51 & $0.19-1.34$ & 0.176 \\
\hline Paradoxical BDR ${ }^{\mathrm{b}}$ & 0.51 & $0.19-1.37$ & 0.187 \\
\hline Paradoxical BDR (propensity score matching analysis) & 0.54 & $0.19-1.57$ & 0.264 \\
\hline
\end{tabular}

a , adjusted for age and sex; ' , adjusted for age, male sex, CAT score, SGRQ-C score, and previous 1-year acute exacerbation. CI, confidence interval; BDR, bronchodilator response; CAT, COPD assessment test; SGRQ-C, COPD-specific version of St. George's Respiratory Questionnaire.

exhibited a paradoxical BDR, following the definition of a paradoxical BDR as described by a previous study (5). Previous studies have reported a paradoxical BDR incidence rate of $4 \%$ of all patients with COPD in the COPD Gene cohort. However, the ECLIPSE cohort reported that 47 (2\%) of 2493 patients showed a paradoxical BDR $(5,12)$. In contrast, the UPLIFT cohort reported a very low incidence of $0.24 \%$, wherein the paradoxical BDR was measured based on GOLD criteria (13). Racial differences may contribute to the differences in incidence of paradoxical BDR (5). In this Asian cohort study, the rate of paradoxical BDR was similar to the results of the ECLIPSE cohort. Further research is needed to determine whether racial differences influence the paradoxical BDR.

The mechanisms associated with a paradoxical BDR after bronchodilator administration have not been fully elucidated. Several possible hypotheses include incorrect inhaler use, bronchospasm from the propellant or the benzalkonium chloride, chlorofluorocarbons, and oleic acid contained in inhalers (6-8). Population differences are observed in the paradoxical response, which might be associated with 8 -receptor polymorphism (5). In this study, higher CRP expression was associated with the paradoxical BDR. Elevated CRP level is associated with reductions in $\mathrm{FEV}_{1}$ and worse outcomes in COPD $(14,15)$. A smaller increase in $\mathrm{FEV}_{1}$ after administration of a bronchodilator is associated with elevated CRP levels in patients with COPD (16). CRP is associated with chronic respiratory inflammation in COPD; therefore, the deterioration of chronic inflammation may be associated with the paradoxical BDR to bronchodilator administration.

In this study, the paradoxical BDR was independently associated with worse dyspnea and a poorer quality of life. In line with this, Bhatt et al. reported that a paradoxical BDR was associated with lower 6MWD and higher mMRC scores (5). Emphysema and airway thickness are independently associated with airway obstruction in patients with COPD (17). Airway thickness but not emphysema 
is significantly increased in the paradoxical BDR group (5). The increased airway thickness may have reduced the response to bronchodilators, consequently contributing to worse dyspnea and poor quality of life. However, paradoxical BDR was not associated with severe acute exacerbations in the present study. In contrast, Bhatt et al. reported that there was an increase in the frequency of severe exacerbation in a paradoxical BDR group after adjusting for confounding factors (5). Bhatt et al. explained that the incidence of severe acute exacerbation was increased in the paradoxical group because there were more African-Americans than whites in the paradoxical BDR group (5). African-Americans with COPD have poorer outcomes than whites (18). Considering racial differences, the present study suggests that Asian populations associated with paradoxical BDR are not prone to acute exacerbations of COPD.

Post-bronchodilator $\mathrm{FEV}_{1}$ and $\mathrm{FVC}$ are key values in diagnosing COPD and assessing the prognosis. However, if the post-bronchodilator $\mathrm{FEV}_{1}$ is used for assessing the prognosis of COPD, airway obstruction can be overestimated. In this study, pre-bronchodilator $\mathrm{FEV}_{1}(\mathrm{~L})$ is higher in the paradoxical BDR group than in the noparadoxical BDR group. However, post-bronchodilator $\mathrm{FEV}_{1}$ and FVC are significantly higher in the noparadoxical BDR group than in the paradoxical BDR group. We found that pre-bronchodilator $\mathrm{FEV}_{1}(\mathrm{~L})$ had a higher AUC for predicting severe acute exacerbations than postbronchodilator $\mathrm{FEV}_{1}(\mathrm{~L})$ in the paradoxical BDR group. While there was no difference between the pre-bronchodilator and post-bronchodilator $\mathrm{FEV}_{1}$ (\% predicted) AUC at predicting severe acute exacerbations, pre-bronchodilator $\mathrm{FEV}_{1}$ measurements may be helpful in assessing disease prognosis in patients with a paradoxical BDR.

There are several limitations to this study. First, we did not assess the serial reversibility tests. Several studies showed that measurements are not consistent when repeated serial BDR tests are administered $(19,20)$. Further study including analysis of the serial measurements is required. Second, there is no validated definition for paradoxical BDR; therefore, we used the definition from a previous study, which defined paradoxical BDR based on the American Thoracic Society criteria (5). Therefore, further studies are necessary to identify whether this definition yields meaningful results in other cohorts. Third, while we found that increased CRP was an independent factor to predict a paradoxical BDR in this study, we cannot exclude the influence of other chronic inflammatory conditions. To reduce this influence, we adjusted for other chronic inflammatory diseases, such as heart disease, diabetes mellitus, and hypertension. After adjusting for these variables, higher CRP was significantly associated with a paradoxical BDR (OR, 1.06; 95\% CI, 1.02-1.10; $\mathrm{P}=0.001$ ). Fourth, although patients with asthma were excluded, some of them may have been included among patients with positive bronchodilator reversibility. It is also possible that these patients underused ICS.

\section{Conclusions}

A paradoxical reduction of $\mathrm{FEV}_{1}$ or $\mathrm{FVC}$ after bronchodilator administration is independently associated with worse respiratory symptoms and a poor quality of life in patients with COPD and may be associated with chronic inflammation in the airway. While paradoxical BDR was not associated with severe acute exacerbations, pre-bronchodilator $\mathrm{FEV}_{1}(\mathrm{~L})$ may be a useful measure for predicting severe acute exacerbations in patients with paradoxical BDR.

\section{Acknowledgments}

Funding: This research was supported by funds (2016ER670100, 2016ER670101, 2016ER670102 and 2018ER670100, 2018ER670101, 2018ER670102) from Research of Korea Centers for Disease Control and Prevention.

\section{Footnote}

Data Sharing Statement: Available at http://dx.doi. org/10.21037/jtd-20-985

Peer Review File: Available at http://dx.doi.org/10.21037/jtd20-985

Conflicts of Interest: All authors have completed the ICMJE uniform disclosure form (available at http://dx.doi. org/10.21037/jtd-20-985). The authors have no conflicts of interest to declare.

Ethical Statement: The authors are accountable for all aspects of the work in ensuring that questions related to the accuracy or integrity of any part of the work are appropriately investigated and resolved. The protocol which was conducted according to the principle expressed in the Declaration of Helsinki (as revised in 2013) was approved 
by the IRB at each participating center including Seoul National University Hospital IRB, Catholic Medical Center Central IRB, Yonsei University Wonju College of Medicine IRB, Severance Hospital IRB, Soonchunhyang University Cheonan Hospital IRB, Ajou University Hospital IRB, Hallym University Dongtan Sacred Heart Hospital IRB, Hallym University Chuncheon Sacred Heart Hospital IRB, Hallym University Pyeongchon Sacred Heart Hospital IRB, Hanyang University Guri Hospital IRB, Konkuk University Hospital IRB, Konkuk University Chungju Hospital IRB, Hallym University Kangdong Sacred Heart Hospital IRB, Hallym University Kangnam Sacred Heart Hospital IRB, Seoul National University Boramae Medical Center IRB, Korea University Guro Hospital IRB, Korea University Anam Hospital IRB, Dongguk University Gyeongju Hospital IRB, Dong-A University Hospital IRB, Gachon University Gil Medical Center IRB, Gangnam Severance Hospital IRB, Kyung Hee University Hospital at Gangdong IRB, Kangbuk Samsung Hospital IRB, Kangwon National University Hospital IRB, Kyungpook National University Hospital IRB, Gyeongsang National University Hospital IRB, Pusan National University Hospital IRB, Soonchunhyang University Bucheon Hospital IRB, Seoul National University Bundang Hospital IRB, CHA Bundang Medical Center, CHA University IRB, Asan Medical Center IRB, Inje University Ilsan Paik Hospital IRB, Eulji General Hospital IRB, Samsung Medical Center IRB, Ulsan University Hospital IRB, Soonchunhyang University Seoul Hospital IRB, Yeungnam University Hospital IRB, Ewha Womans University Mokdong Hospital IRB, Inha University Hospital IRB, Chonbuk National University Hospital IRB, and Jeju National University Hospital IRB. All patients provided written informed consent for participation from each center.

Open Access Statement: This is an Open Access article distributed in accordance with the Creative Commons Attribution-NonCommercial-NoDerivs 4.0 International License (CC BY-NC-ND 4.0), which permits the noncommercial replication and distribution of the article with the strict proviso that no changes or edits are made and the original work is properly cited (including links to both the formal publication through the relevant DOI and the license). See: https://creativecommons.org/licenses/by-nc-nd/4.0/.

\section{References}

1. Vogelmeier CF, Criner GJ, Martinez FJ, et al. Global
Strategy for the Diagnosis, Management, and Prevention of Chronic Obstructive Lung Disease 2017 Report.

GOLD Executive Summary. Am J Respir Crit Care Med 2017;195:557-82.

2. Albert P, Agusti A, Edwards L, et al. Bronchodilator responsiveness as a phenotypic characteristic of established chronic obstructive pulmonary disease. Thorax 2012;67:701-8.

3. Kim J, Kim WJ, Lee CH, et al. Which bronchodilator reversibility criteria can predict severe acute exacerbation in chronic obstructive pulmonary disease patients? Respir Res 2017;18:107.

4. Hansen JE, Porszasz J. Counterpoint: Is an increase in $\mathrm{FEV}$ and/or FVC $\geq 12 \%$ of control and $\geq 200 \mathrm{~mL}$ the best way to assess positive bronchodilator response? No. Chest 2014;146:538-41.

5. Bhatt SP, Wells JM, Kim V, et al. Radiological correlates and clinical implications of the paradoxical lung function response to beta(2) agonists: an observational study. Lancet Respir Med 2014;2:911-8.

6. Nicklas RA. Paradoxical bronchospasm associated with the use of inhaled beta agonists. J Allergy Clin Immunol 1990;85:959-64.

7. "Inactive" ingredients in pharmaceutical products: update (subject review). American Academy of Pediatrics Committee on Drugs. Pediatrics 1997;99:268-78.

8. Spooner LM, Olin JL. Paradoxical bronchoconstriction with albuterol administered by metered-dose inhaler and nebulizer solution. Ann Pharmacother 2005;39:1924-7.

9. Standardization of Spirometry, 1994 Update. American Thoracic Society. Am J Respir Crit Care Med 1995;152:1107-36.

10. Laboratories ATSCoPSfCPF. ATS statement: guidelines for the six-minute walk test. Am J Respir Crit Care Med 2002;166:111-7.

11. Lung function testing: selection of reference values and interpretative strategies. American Thoracic Society. Am Rev Respir Dis 1991;144:1202-18.

12. Hurst JR, Vestbo J, Anzueto A, et al. Susceptibility to exacerbation in chronic obstructive pulmonary disease. $\mathrm{N}$ Engl J Med 2010;363:1128-38.

13. Tashkin DP, Celli B, Decramer M, et al. Bronchodilator responsiveness in patients with COPD. Eur Respir J 2008;31:742-50.

14. Zhang Y, Bunjhoo H, Xiong W, et al. Association between C-reactive protein concentration and chronic obstructive pulmonary disease: a systematic review and meta-analysis. J Int Med Res 2012;40:1629-35. 
15. El-Deek SE, Makhlouf HA, Saleem TH, et al. Surfactant protein D, soluble intercellular adhesion molecule-1 and high-sensitivity C-reactive protein as biomarkers of chronic obstructive pulmonary disease. Med Princ Pract 2013;22:469-74.

16. Broekhuizen R, Wouters EF, Creutzberg EC, et al. Raised CRP levels mark metabolic and functional impairment in advanced COPD. Thorax 2006;61:17-22.

17. Patel BD, Coxson HO, Pillai SG, et al. Airway wall thickening and emphysema show independent familial aggregation in chronic obstructive pulmonary disease. Am

Cite this article as: Shin HJ, Kim TO, Kim YI, Kim SH, Kim HK, Kim YH, Byun MK, Jung KS, Yoo KH, Lee JS, Lim SC; KOCOSS Cohort Study Group. The paradoxical response to short-acting bronchodilator administration in patients with chronic obstructive pulmonary disease. J Thorac Dis 2021;13(2):511-520. doi: 10.21037/jtd-20-985
J Respir Crit Care Med 2008;178:500-5.

18. Han MK, Curran-Everett D, Dransfield MT, et al. Racial differences in quality of life in patients with COPD. Chest 2011;140:1169-76.

19. Mahler DA, Donohue JF, Barbee RA, et al. Efficacy of salmeterol xinafoate in the treatment of COPD. Chest 1999;115:957-65.

20. Tashkin D, Kesten S. Long-term treatment benefits with tiotropium in COPD patients with and without short-term bronchodilator responses. Chest 2003;123:1441-9. 